University of Nebraska - Lincoln

DigitalCommons@University of Nebraska - Lincoln

USDA National Wildlife Research Center - Staff Publications
U.S. Department of Agriculture: Animal and Plant Health Inspection Service

2019

\title{
Mind the Gap: Experimental Tests to Improve Efficacy of Fladry for Nonlethal Management of Coyotes
}

\author{
Julie K. Young \\ USDA National Wildlife Research Center, julie.k.young@aphis.usda.gov \\ John Draper \\ Utah State University \\ Stewart Breck \\ USDA National Wildlife Research Center
}

Follow this and additional works at: https://digitalcommons.unl.edu/icwdm_usdanwrc

Part of the Natural Resources and Conservation Commons, Natural Resources Management and Policy Commons, Other Environmental Sciences Commons, Other Veterinary Medicine Commons, Population Biology Commons, Terrestrial and Aquatic Ecology Commons, Veterinary Infectious Diseases Commons, Veterinary Microbiology and Immunobiology Commons, Veterinary Preventive Medicine, Epidemiology, and Public Health Commons, and the Zoology Commons

Young, Julie K.; Draper, John; and Breck, Stewart, "Mind the Gap: Experimental Tests to Improve Efficacy of Fladry for Nonlethal Management of Coyotes" (2019). USDA National Wildlife Research Center - Staff Publications. 2253.

https://digitalcommons.unl.edu/icwdm_usdanwrc/2253

This Article is brought to you for free and open access by the U.S. Department of Agriculture: Animal and Plant Health Inspection Service at DigitalCommons@University of Nebraska - Lincoln. It has been accepted for inclusion in USDA National Wildlife Research Center - Staff Publications by an authorized administrator of DigitalCommons@University of Nebraska - Lincoln. 
Original Article

\title{
Mind the Gap: Experimental Tests to Improve Efficacy of Fladry for Nonlethal Management of Coyotes
}

\author{
JULIE K. YOUNG ${ }^{1}{ }^{2}$ U.S. Department of Agriculture, National Wildife Research Center, Predator Research Facility, Millville, UT 84326, USA; and \\ Department of Wildland Resources, Utah State University, Logan, UT 84322, USA \\ JOHN DRAPER, Ecology Center, Utah State University, Logan, UT 84322, USA \\ STEWART BRECK, U.S. Department of Agriculture, National Wildlife Research Center, Predator Research Facility, Fort Collins, CO 80521, USA
}

\begin{abstract}
Coyotes (Canis latrans) are the top predator of livestock in the contiguous United States. Developing more effective nonlethal tools to prevent coyote depredation will facilitate coexistence between livestock producers and coyotes. Fladry is a nonlethal deterrent designed to defend livestock by creating a visual barrier to wolves (C. lupus). Fladry may also be effective with coyotes, but large gap spacing between flags may reduce its efficacy. To address this issue, we performed 2 experiments on captive coyotes using fladry modified to reduce gap spacing at the U.S. Department of Agriculture, Predator Research Facility in Millville, Utah, USA, during 2015-2016 and 2017-2018. In 2015-2016, we tested 2 styles for attaching flags (top-knot and shower-curtain) to the rope-line that reduce gaps by preventing coiling of individual flags. In 2017-2018, we tested the efficacy of gap spacing $(27.9 \mathrm{~cm}$ vs. $45.7 \mathrm{~cm})$ between flags for preventing coyote crossings. For both tests, we compared the time until coyotes crossed the fladry between treatment types. We found no differences in time to crossing between the 2 attachment designs. In our second experiment, fladry with smaller gaps between flags had greater efficacy of preventing coyote crossings than did fladry with larger gaps. Our results also indicated that for each additional minute coyotes spent interacting with fladry overall (i.e., increased persistent behavior), survival of the barrier decreased. These results suggest that persistent coyotes may overcome neophobia more rapidly than coyotes that do not exhibit persistent behaviors. Furthermore, use of top-knot fladry and coyote-width spacing will increase protection of livestock from coyotes. (C) 2019 The Wildlife Society.
\end{abstract}

KEY WORDS Canis latrans, carnivore, conservation, coyote, livestock depredation, nonlethal control, predator management.

Many human-wildlife conflicts are related to livestock depredation caused by carnivores that result in economic losses to affected stakeholders. Predator control programs to reduce livestock depredations are known to be a significant source of mortality for carnivores (Woodroffe and Ginsberg 1998, Gittleman et al. 2001, Woodroffe et al. 2005, Broekhuis et al. 2017). Although livestock depredation can be mitigated through the use of lethal and nonlethal predator management techniques, nonlethal tools are often employed first. However, few nonlethal tools have been experimentally tested and promotion of nonlethal tools without science-based evidence can reduce trust between livestock producers who could benefit from the use of

Received: 3 August 2018; Accepted: 6 March 2019

Published: 00 Month 2019

${ }^{1}$ E-mail: julie.k.young@aphis.usda.gov nonlethal tools and conservationists desiring increased human-carnivore coexistence (Miller et al. 2016, Eklund et al. 2017, Scasta et al. 2017).

One nonlethal tool that is gaining popularity among livestock producers and conservationists alike is fladry. Fladry is an effective nonlethal tool that was developed to protect vulnerable livestock in pastures from wolves (Canis lupus; Musiani and Visalberghi 2001, Musiani et al. 2003, Mettler and Shivik 2007). It consists of a strand of flags measuring approximately $50 \mathrm{~cm} \times 10 \mathrm{~cm}$ that are sewn onto nylon rope at $45-\mathrm{cm}$ intervals. Fladry acts as a primary repellent by taking advantage of neophobic behavior of wolves and relies on producing a flight or startle response to deter them (Shivik 2006). When flags are hung just above the ground, their motion in the wind creates a novel, visually frightening stimulus that can prevent wolves from entering the protected area for 60-75 days (Musiani and Visalberghi 2001, Musiani et al. 2003, Mettler and Shivik 2007, Davidson-Nelson and 
Gehring 2010). Modifications to fladry have prolonged its effectiveness by incorporating an aversive stimulus; the nylon twine that supports the flagging can be replaced with an electrified wire that emits a nonharmful, but painful, shock when an animal touches it (Lance et al. 2011). Electrified fladry uses an aversive stimulus to reinforce the initial fear that fladry promotes, thus providing a longer lasting nonlethal tool.

Although designed for wolves, fladry may also be effective for deterring coyotes (C. latrans; Mettler and Shivik 2007). Coyote depredation of livestock remains the most common and broadly distributed human-wildlife conflict throughout the United States, so increasing efficacy of fladry could facilitate coexistence of coyotes and livestock (United States Department of Agriculture [USDA]-National Agricultural Statistics Service 2011). This is especially important because modifications may only need to result in a small increase in effectiveness. For example, Rashford et al. (2010) showed that a $1 \%$ reduction in livestock mortality from depredation would result in a given livestock operation becoming economically viable.

Observations of coyotes interacting with fladry in previous studies suggest coyotes are likely to overcome their neophobia more rapidly than wolves by slipping through gaps between the flags and rendering it ineffective (Davidson-Nelson and Gehring 2010, Young et al. 2018; Fig. 1). Once fladry is crossed by animals, it is postulated that they will overcome their fear and fladry will no longer be perceived as a barrier (Musiani et al. 2003). Thus, enhancing the design to prevent the initial crossing by coyotes is important for improving the effectiveness of fladry. It is possible that fladry in its current design, which was originally created to deter wolves (i.e., wolffladry), is not appropriate for coyotes. At least one study showed that fladry was effective for wolves, but had no effect on coyotes (Davidson-Nelson and Gehring 2010). Further, anecdotal evidence from use of fladry on working livestock operations highlighted that individual flags coil in the wind and created gaps in the fladry that facilitated crossings by wild canids, especially coyotes. To address the latter case, 2 new designs were identified that reduced coiling and may therefore increase efficacy (Young et al. 2015). However, these designs were not tested on coyotes during that study.

Improvements to this nonlethal tool may not increase efficacy uniformly because behavioral responses and problem-solving skills of individual coyotes differ. Traits such as persistence and innovation that vary among individuals have been shown to affect problem-solving capability in carnivores, with increases in persistence and innovation typically resulting in greater problem-solving success (Benson-Amram and Holekamp 2012). Thus, measuring the efficacy of a modified nonlethal tool for coyotes should include metrics of animal behavior or persistence for a more accurate assessment.

Our goal was to develop a more effective nonlethal tool for coyote management by testing 2 modifications made to fladry that reduced gaps, while considering the potential influence of individual variation in coyote behavior. We performed 2 experiments to reach this goal. First, we compared 2 attachment designs-shower curtain and top-knot-developed to reduce gaps caused by coiling of flags on traditionally attached fladry (i.e., sewn directly onto line; Young et al. 2015), to determine if one of the 2 designs resulted in longer latency to cross by coyotes. We then made a second modification by decreasing the spacing between flags to determine whether this would make fladry more effective at preventing coyote crossings. Our logic was that efficacy may increase by decreasing the spacing between flags to better match the smaller size of coyotes (hereafter called coyote-fladry) relative to the size of wolves and traditional flag spacing (hereafter called wolf-fladry). We experimentally tested coyote- and wolffladry on captive coyotes and compared the efficacy of each design to determine if flag spacing was an important modification. In both experiments, we defined efficacy as latency to cross. Finally, we included behavioral measures of coyote persistence relative to the fladry-spacing treatments to determine if there was a relationship between how much a coyote interacted with the fladry barrier and the coyote's propensity to cross it.

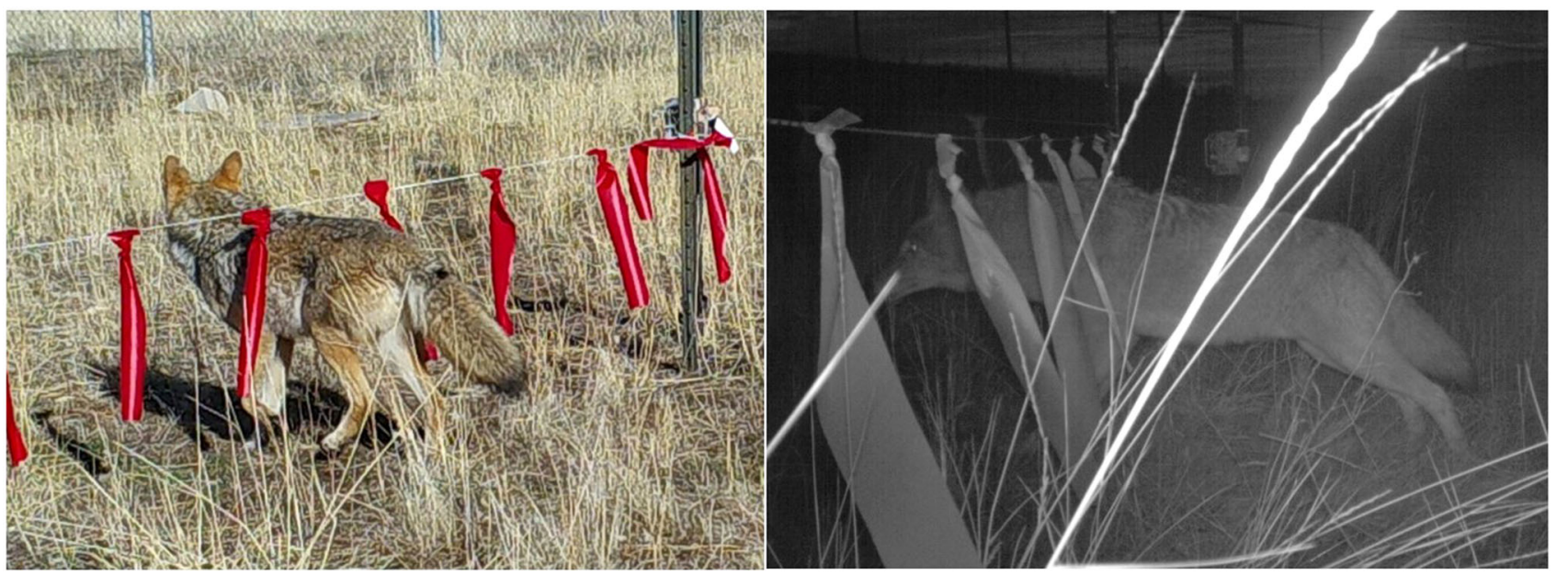

Figure 1. Camera-trap photographs of captive coyotes at the United States Department of Agriculture-Predator Research Facility in Millville, Utah, USA, crossing wolf-fladry (i.e., fladry with 45.7 -cm gap between flags) by walking between flags during daylight and night hours during 2015 . 


\section{STUDY AREA}

Captive coyotes were maintained at the USDA-National Wildlife Research Center's Predator Research Facility in Millville, Utah, USA. The facility was 66.4 ha and housed up to 100 captive coyotes, traditionally kept as male-female pairs in outdoor enclosures ranging between 0.1 ha and 1.0 ha. Enclosures contained natural, grassland vegetation. Captive coyotes were fed $650 \mathrm{~g}$ of commercial mink food (Fur Breeders Agricultural Cooperative, Logan, UT, USA) daily, using a technique referred to as scatter-feeding, where the food is distributed broadly within each enclosure. Water was provided ad libitum.

\section{METHODS}

We first tested the 2 designs from Young et al. (2015) on male-female pairs of captive coyotes that had not previously been exposed to fladry. This phase of study was divided into 2 time periods, with the first occurring in the winter (28 Oct-9 Dec 2015) and the second occurring in summer (6 Jun-20 Jul 2016). Four pie-shaped enclosures (1.0 ha/enclosure), divided into large and small sections for ease of capture, were used to house male-female coyote pairs. The pie-shaped enclosures were built in a semicircle with 2-mwide alleyways separating each enclosure and arranged around a central observation building. Each pair stayed in the same enclosure for the duration of the experiment, which consisted of a control and experimental phase. New coyote pairs were placed in each pie pen 3 times/season.

To ensure all coyotes would be willing to cross a visual barrier to consume their daily food ration near a novel object (i.e., camera trap), we first placed a nylon twine rope (i.e., the horizontal base on which to attach the fladry) at approximately $50 \mathrm{~cm}$ above ground level diagonally across a corner of each pie-shaped enclosure and used video or camera traps to record coyote crossings into the corner during the 5-day control period. The video recorder recorded the area within and around the fladry line, and the corner where food was placed. The camera trap was placed along the enclosure fence, focused parallel to the fladry line, and angled to capture interactions with the fladry line and after a crossing occurred. We placed food within the center of the corner area, behind the rope line, and coyotes were observed to cross it and consume the food to be included on fladry testing. All coyotes performed this task.

We randomly assigned each pair of coyotes to one of the 2 designs detailed in Young et al. (2015): top-knot or shower curtain. The pre-experiment rope was replaced with a rope affixed with the assigned fladry design, such that the bottoms of the flags were 7-12 cm above ground level. Each morning for 10 consecutive days, one person would enter the enclosure, replace secure digital (SD) cards and batteries as needed, and place $650 \mathrm{~g}$ of the normal food for captive coyotes in the center of the protected corner, behind the fladry. The person returned each afternoon and fed coyotes their normal $650-\mathrm{g}$ food ration using standard feeding protocol, but away from the area where fladry was hung. We used recorded video and photographs to observe when coyotes crossed the fladry. We coded observations as the latency to first cross, recorded in days since application of the fladry line.

We selected one design for the second experiment comparing spacing of flagging based on results comparing the 2 attachment designs. For this experiment, we used only captive coyotes that were not used during the first experiment or otherwise exposed to fladry prior to testing. Coyote pairs were housed in 1 of 2 enclosure designs - pie-shaped or pack enclosures-during the study. Like pie-shaped enclosures, pack enclosures were large (0.6-ha) outdoor enclosures but differed in their shape from pie-shaped enclosures in that pack enclosures were octagonal. They were situated in 2 rows of 4 , southwest of the pie-shaped enclosures. To balance the design among the 2 fladry types, detailed below, we subjected 2 sets of coyotes to fladry testing in the 4 pie-shaped enclosures. We used only one set of coyotes in the 8 pack enclosures. All tests occurred between November 2017 and February 2018.

In all enclosures, we designated a small section as a protected area ( $\sim 5 \%$ of the enclosure). The placement was consistent across enclosures, approximately $12 \mathrm{~m}$ from an entrance gate for humans. Prior to the trials, we installed 8 fence posts and 5 camera traps/enclosure. We set 4 fence posts in a $5 \times 5-\mathrm{m}$ square and used them as the corners for the fladry to be attached. We set the other 4 fence posts diagonally approximately $0.5 \mathrm{~m}$ outward from these corners for the camera traps to be attached. We placed 4 camera traps approximately $50 \mathrm{~cm}$ above ground on these outer fence posts and angled them to run parallel to the fladry line. We determined the angle of cameras in advance by setting several $5-\mathrm{m}$ rows of fladry in a vacant field and walking a coyote-sized domestic dog (Canis l. familiaris) around the area. We subsequently used the angle that ensured photographs were taken of coyotes interacting with the fladry, but reduced the number of photographs taken due to flags moving in the wind. We placed the fifth camera trap at the top of one corner fencepost used for fladry and angled it downward toward the middle of the square to be enclosed by fladry. We synchronized all cameras for date and time and programmed most to take 3-5-shot bursts with a 1-s delay between shots. Some of the camera models were more prone to false triggers, so we programed these with a 10-20-s delay between burst triggers.

Each day, 1-2 people entered the enclosure at approximately 0930 and placed approximately $650 \mathrm{~g}$ of the normal food for captive coyotes at the facility within the center of the area designated to be protected. After 5 days, we installed coyote- or wolf-fladry around the protected area. Half of the pairs were randomly selected to receive wolffladry and half received coyote-fladry. Wolf-fladry was traditional fladry, with gaps between flags at $45.7 \mathrm{~cm}$. To determine the appropriate gap between flags for coyote-fladry, we determined the ratio of body width to fladry width for wolves and applied that ratio for coyotes. Body width of wolves was determined using records from wild wolves in Minnesota, USA, and body width of coyotes was determined from measurements of captive coyotes. The 
calculation resulted in coyote-fladry having a spacing of $27.9 \mathrm{~cm}$ between flags.

During fladry tests, the same 2 people continued to place food within the center of the square, then surrounded by coyote- or wolf-fladry, at the same time each day for up to 28 consecutive days. They also switched out SD cards multiple days each week before replenishing food. Trials ended after 28 days if neither coyote crossed the fladry, but ended earlier if $\geq 1$ of the 2 coyotes in the enclosure crossed the fladry boundary. Every trial continued for $\geq 24 \mathrm{hr}$ after coyotes crossed the fladry. This occurred because we only checked fladry and camera traps up to 1 time/day, resulting in most crossings not being detected until nearly $24 \mathrm{hr}$ after they occurred. It also provided camera-trap data to evaluate post-cross behavioral interactions with fladry. Many trials ran $48-72 \mathrm{hr}$ after crossings because of the natural delay in photo review; photos were not reviewed on most weekends, so we only evaluated camera-trap data for up to $24 \mathrm{hr}$ after crossing to ensure consistency in data availability. Each trial day at approximately 1600, 1 of the 2 personnel conducting the morning fladry feeding also entered the enclosures using the same gate and provided food for the coyotes via scatterfeeding $\geq 50 \mathrm{~m}$ from the fladry.

We used camera-trap data to code all events when coyotes interacted with fladry. Multiple cameras were used in each enclosure, so an event included all photos taken at the same or consecutive time(s). If $>2$ min passed between photos, we recorded the series of photos. For each event, we recorded the start and end time, number of photos included in the event, coyote behavior, number of coyotes present (1 or 2), and location of the coyote. We defined behavior as falling into 1 of 3 categories: eating, interacting with fladry, and other. Eating was used when we observed the coyote to be consuming the food placed in the middle of the square. Interacting with fladry included biting, pawing, or investigating behavior. Other behavior included any event where a coyote was clearly caught on camera incidentally, such as walking along a nearby trail. We defined location in 3 categories: outside of the fladry, touching or partial cross of the fladry, and crossed. We only used crossed when the coyote's entire body was within the fladry-protected area. When possible, we also recorded individual identification. One person coded event data from the camera traps for all pens and pairs to prevent any inter-observer error. To account for intra-observer error and observer drift, we selected multiple random times from each coyote pair and coded by a second individual to compare with coded data for consistency.

For both experiments, we analyzed data in a nest survival model to allow for right censoring and variation in survival across time. We formulated and tested models using the RMark package in Program R (Laake and Rexstad 2008, R Core Team 2018). We defined survival as the "survival" of the fladry as an effective barrier preventing coyote crossings and access to the food. For the first experiment, we evaluated differences in survival rates using a Wald $Z$-test. For the second experiment, our sample size did not allow for consideration of any additive or interactive models.
Therefore, we evaluated all single-variable models for significance with a Wald $Z$-test at $\alpha=0.10$. We chose this significance level because of our small sample size and to avoid type II error. In addition to treatment, we evaluated average age of the coyotes in each pair, daily average testing (in minutes), and latency to first approach (in minutes) to identify additional factors effecting efficacy of fladry. Only significant results related to these factors are reported in the results. All research met humane standards and was approved by the USDA-National Wildlife Research Center's Institutional Animal Care and Use Committee (QA-2535 and QA-2804).

\section{RESULTS}

For the first experiment, we used 24 male-female pairs of captive coyotes, ranging in age from 2 to 9 years old (average $=5.2 ; \mathrm{SE}=0.3 \mathrm{yr}$ old). All test coyotes crossed the control-rope boundary for food $(n=48)$ on the first day of the testing period. The shower-curtain design was crossed by coyotes in 2 enclosures on the first day of testing, with additional pairs of coyotes crossing on days 4, 5, and 9 (2 enclosures); fladry was not crossed in the remaining enclosures for the entire 10-day testing period. Coyotes crossed the top-knot design on days 2, 3, and 5 (2 enclosures), with the remainder surviving the entire 10-day testing period. There was no statistical difference between survival rates of the 2 fladry designs-both designs had survival rates of 0.55 ( $\mathrm{SE}=0.13$; shower-curtain) and 0.68 ( $\mathrm{SE}=0.13$; top-knot). There was no difference in the 2 distributions (Wald $Z=0.70, P=0.24$; Fig. 2). With no difference in efficacy between the 2 types of fladry, we elected to use the top-knot design in the second experiment for logistical reasons.

We used the remaining male-female pairs of coyotes that had not been exposed to fladry at the facility previously $(n=16)$ for the second experiment. These coyotes were of similar age to the ones used in the first experiment, ranging from 1 to 8 years of age (average $=4.0 ; \mathrm{SE}=0.6 \mathrm{yr}$ old). Coyotes crossed the fladry barrier in 7 out of 16 trials. No coyotes crossed the coyote-fladry on day $1, \geq 1$ coyote within an enclosure crossed on day 2 , and a second crossed on day 10. At least one coyote in an enclosure crossed the wolffladry on day 1 , with $\geq 1$ coyote in other enclosures crossing on days 2, 4 (2 enclosures), and 15.

The single-variable models that considered only the fladry treatment and amount of time the coyotes spent testing the fladry showed a significant effect on the overall survival of fladry (Table 1). The coyote-fladry increased estimated survival of the barrier from 0.41 to $0.76(P=0.06)$ over the wolf-fladry (Fig. 2). Each additional minute of coyotes testing the fladry decreased daily survival by a small $(0.0002)$ but statistically significant amount $(P=0.01)$. In pens where fladry barriers were crossed, coyotes from most pens (6 out of 7) crossed repeatedly in the following $24 \mathrm{hr}$ after initial crossing. Coyotes in one pen crossed 70 additional times over the subsequent $24 \mathrm{hr}$, with less frequent crossings in the 6 other pens $(1,2,3,7,7$, and 10 times). 

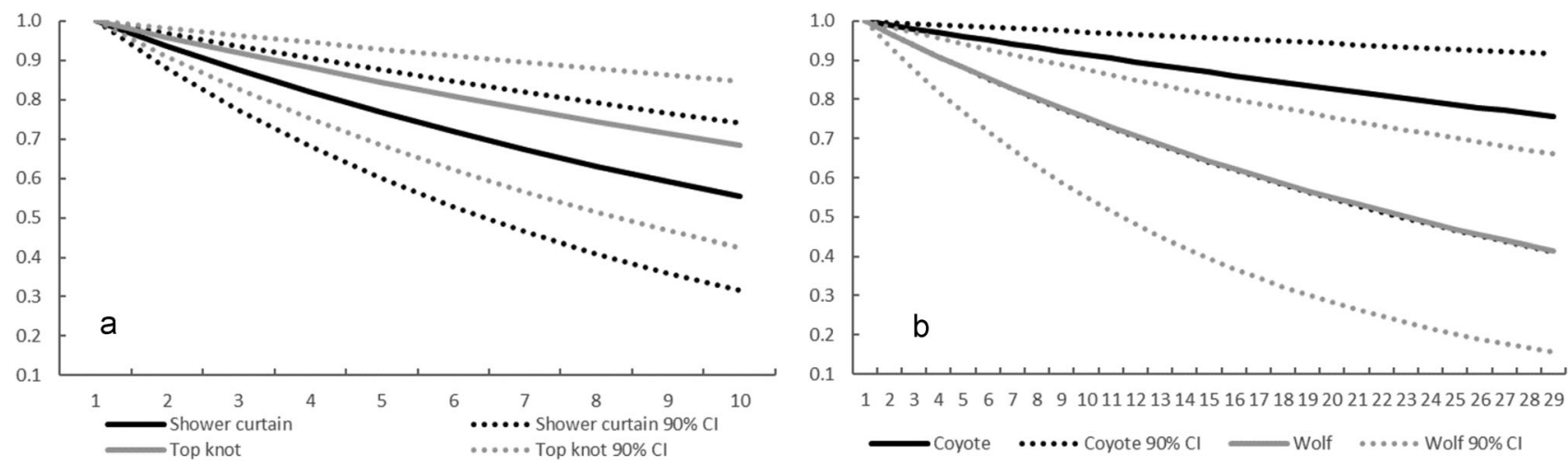

Figure 2. Survival of exclusionary efficacy for (a) shower-curtain and top-knot fladry, where the attachment differed in their design to reduce coiling of individual flags, and (b) wolf- and coyote-fladry, where the spacing between flags differed at the United States Department of Agriculture-Predator Research Facility in Millville, Utah, USA, during 2015. Wolf-fladry had a gap of $45.7 \mathrm{~cm}$ between flags. Coyote-fladry had a gap of $27.9 \mathrm{~cm}$ between flags. Survival was measured as latency (in days) for captive coyotes to cross the fladry barrier.

Table 1. Single-variable survival model estimates for time to cross wolf- or coyote-fladry by captive coyotes at the Predator Research Facility in Millville, Utah, USA, during 2017. A single standard error is reported for all continuous variables, while the standard error of each categorical variable is reported in the one categorical comparison.

\begin{tabular}{lcccccc}
\hline Variable tested & Model & npar & $\boldsymbol{\Delta}$ Daily survival & SE & $\boldsymbol{P}$ & Increment of effect \\
\hline Testing duration & S( $\sim$ Testing $)$ & 2 & -0.0002 & 0.008 & 0.01 & Per additional minute of testing \\
Wolf vs. coyote & S( Treatment $)$ & 2 & -0.0211 & $0.007^{\mathrm{a}}, 0.014^{\mathrm{b}}$ & 0.06 & Wolf- vs. coyote-fladry \\
Age & S( Age) & 2 & $<0.0000$ & $<0.000$ & 0.48 & Per additional year of age \\
Time to first test & S( FirstTest $)$ & 2 & $<0.0000$ & 0.014 & 0.71 & Per each additional minute before first test \\
Null & S( 1) & 1 & NA & 0.007 & $<0.001$ & \\
\hline
\end{tabular}

${ }^{a}$ Wolf.

${ }^{\mathrm{b}}$ Coyote.

\section{DISCUSSION}

Maximizing the efficacy of nonlethal tools is important to facilitate their widespread adoption (Scasta et al. 2017). One issue that compromises efficacy of fladry are gaps between flags that enhance the ability of wild canids to overcome their fear and cross the visual boundary. Flags that coil on themselves and create large gaps are clearly a problem, but so are built-in gaps between flags that may be inherently too wide for the focal species (Young et al. 2015). Our work addressed both these issues for developing a fladry product that is more appropriate for coyotes.

In our first experiment, we found that both designs known to reduce coiling of individual flags worked equally well at preventing captive coyotes from crossing the visual barrier. We chose the top-knot design for further modifications because it was logistically easier to create and survival curves suggested a slightly better response, albeit not significantly different from survival curves for the shower-curtain design. For the top-knot design, fladry was delivered in its original stitch design, but with an additional $7.6 \mathrm{~cm}$ of length/flag so that we could handtie the top-knot for each flag while maintaining the traditional length. However, we recognize that hand-tying top-knots on all flags may not be feasible in a field setting where several kilometers of fladry may be needed. Identifying a method to attach the fladry using either of the modified designs would provide a better step moving forward.
Our second experiment indicated that reducing the spacing between flagging to approximately $28 \mathrm{~cm}$ nearly doubled the efficacy over standard wolf-fladry. This aspect of the design was possible with the manufacturer, so no manual modification was needed. We decided on this spacing based on relative morphometric measurements of wolves and coyotes and the logic that flags touching an animal were presumably scarier than if wild canids could pass through without contacting the flags. This is likely even more relevant with electrified fladry. This is a reasonable assumption because most documented crossings of fladry involved coyotes crossing between flags and making contact with rope, with a few also attempting to duck underneath them (Davidson-Nelson and Gehring 2010). We also used this modification under the assumption the original wolf-fladry was designed with morphometrics of the wolf as a consideration, but did not find published evidence for this.

In the second experiment, we also showed that coyotes willing to interact with the fladry did so more each day, and can be defined as more persistent. Persistence is a measure of task-directed motivation often linked to food motivation (Griffin and Guez 2014). Persistent coyotes have previously been shown to more likely interact with a novel repellent (Darrow and Shivik 2009). In our study, coyotes identified as persistent were more likely to cross fladry. Persistence 
increase an animal's ability to succeed at a new task, and our data support the growing body of literature on this topic across a variety of taxa (e.g., Day et al. 2003, Tebbich et al. 2010, Griffin et al. 2014), including other carnivores (Benson-Amram and Holekamp 2012, Thornton and Samson 2012). However, it is difficult to untangle persistence and habituation. Animals may habituate to novel objects and stop being repelled by them over time (McCullough 1982). Coyotes that we defined as more persistent may also habituate (i.e., show reduced neophobia) to novel objects more quickly, similar to how social status may influence coyote neophobia (Mettler and Shivik 2007, Darrow and Shivik 2009). What remains less clear in the literature is whether having traits such as persistence or reduced neophobia are related to foraging; this could refine our understanding of which coyotes are most likely to kill livestock (Knowlton et al. 1999, Sacks et al. 1999).

In both experiments, most coyotes that crossed fladry did so within the first 4 days fladry was hung. This is likely more rapid than would be expected for wild coyotes, as captive coyotes were highly incentivized to cross fladry in both experiments. First, captive coyotes occupied relatively small enclosures compared with typical home ranges of wild coyotes (ranging between $2.5 \mathrm{~km}^{2}$ and $60 \mathrm{~km}^{2}$; Ś́lek et al. 2015). Our captive coyotes would likely have seen the fladry from any part of their enclosure because of the low grassland vegetation and enclosure size. Enclosure size would also mean coyotes would have exponentially greater opportunity to interact with the fladry compared with wild animals. Furthermore, fladry areas represented a relatively large proportion of their enclosure, which is unlikely to occur in the wild where fladry typically protects pastures of approximately $0.16 \mathrm{~km}^{2}$.

Second, captive coyotes did not have another source of food for several hours after food was placed behind the fladry barrier. Captive coyotes are fed by animal care staff daily and do not have access to alternative food sources, such as native prey. During both experiments, food was placed within areas protected by fladry each morning and their daily food ration was provided outside of fladry-protected areas in late afternoon. Thus, coyotes on trial were extremely food-motivated to cross boundaries. It is expected that innovation, like that needed for coyotes to cross the fladry, should occur more readily in times of necessity (Reader and Laland 2003, Clayton 2004). In the wild, coyotes would have access to alternative sources of food outside of the area being protected by fladry and, therefore, have less necessity to problem solve the fladry. Adding to this food motivation, is the fact that we fed coyotes in the area where fladry was placed for several days leading up to the experiments to ensure they would utilize the area if no barrier existed. Captive coyotes may have associated this location with daily feeding and simply been attempting to maintain this daily activity pattern.

Third, we did not use electric fladry (i.e., turbo fladry), which is used most commonly on working livestock operations and has been shown to increase efficacy (Lance et al. 2011). We opted against electrifying fladry lines to decrease costs for trials and increase standardization across pens. In some cases, electric systems temporarily stop working and that would have affected our ability to compare designs. Although we believe our results apply to field settings because captive coyotes at the facility behave similarly to wild coyotes (Shivik et al. 2009), we also encourage additional data collection on wild coyotes to validate our findings and determine if longer latency to cross times are achieved.

Although our results suggest the modified design is better at preventing coyotes from crossing, we note that we did not test whether the modifications affect wolf crossings. In areas where wolves are the primary threat to livestock, these modifications may not be necessary, especially if a livestock producer already owns traditionally attached wolf-fladry. However, if coyotes are the primary threat, then we suggest using these modifications, even in areas where wolves may also occur. It is unlikely that the space reduction and attachment modifications would reduce efficacy for wolves. Further, it may help prevent younger wolves, more similar in size to coyotes, from crossing.

Finally, our research used an experimental design that is rare in testing methods that reduce carnivore-livestock conflict (Miller et al. 2016, Eklund et al. 2017, Scasta et al. 2017, Moreira-Arce et al. 2018, van Eeden et al. 2018). Though important, carrying out experiment-based studies requires several steps often not possible when conducting research on conflict with carnivores. For example, livestock depredations may significantly affect an individual producer, but the frequency and overall number of attacks are quite low relative to the needs of sample sizes for rigorous experimental design under field conditions. Further, carnivores are often elusive and difficult to individually identify (e.g., Alexander and Gese 2018). Even with the aid of using captive animals in our experiments, we were unable to consistently identify individuals via camera-trapping. This issue, along with our overall sample size, together limited us to single-factor analysis. Having additional animals may have provided more insight into the mechanisms influencing coyote behavior toward fladry and improved the strength of our findings.

\section{ACKNOWLEDGMENTS}

We thank A. Laramie, G. Chivee, A. Baca, C. Bond, N. Souza, C. Eliason, and B. Henke with their help conducting captive trials and coding data. S. Brummer, M. Davis, N. Floyd, B. Jolley, A. Merical, J. Schultz, E. Stephenson, and several volunteers provided substantial assistance at the Predator Research Facility. Z. Strong and R. Much were valuable in early discussions about study design. We thank E. Gese for wolf morphology data and Z. Z. Bottom for volunteering as camera-trap tester. We are thankful to the Associate Editor J. Hinton and 2 anonymous reviewers for providing excellent feedback of our manuscript. This research was supported by the intramural research program of the U.S. Department of Agriculture, National Wildlife Research Center. Any use of trade, firm, or product names is for descriptive purposes only and does not imply 
endorsement by the U.S. Government. The findings and conclusions in this publication have not been formally disseminated by the U.S. Department of Agriculture and should not be construed to represent any agency determination or policy.

\section{LITERATURE CITED}

Alexander, P. D., and E. M. Gese. 2018. Identifying individual cougars (Puma concolor) in remote camera images-implications for population estimates. Wildlife Research 45:274-281.

Benson-Amram, S., and K. E. Holekamp. 2012. Innovative problem solving by wild spotted hyenas. Proceeding of the Royal Society B 279:4087-4095.

Broekhuis, F., S. A. Cushman, and N. B. Elliot. 2017. Identification of human-carnivore conflict hotspots to prioritize mitigation efforts. Ecology and Evolution 7:10630-10639.

Clayton, N. S. 2004. Is necessity the mother of innovation? Trends in Cognitive Science 8:98-99.

Darrow, P. A., and J. A. Shivik. 2009. Bold, shy, and persistent: variable coyote response to light and sound stimuli. Applied Animal Behaviour Science 116:82-87.

Davidson-Nelson, S. J., and T. M. Gehring. 2010. Testing fladry as a nonlethal management tool for wolves and coyotes in Michigan. Human-Wildlife Interactions 4:87-94.

Day, R. L., R. L. Coe, J. R. Kendal, and K. N. Laland. 2003. Neophilia, innovation and social learning: a study of intergeneric differences in callitrichid monkeys. Animal Behaviour 65:559-571.

Eklund, A., J. V. López-Bao, M. Tourani, G. Chapron, and J. Frank. 2017. Limited evidence on the effectiveness of interventions to reduce livestock predation by large carnivores. Scientific Reports 7:2097.

Gittleman, J. L., S. M. Funk, D. W. Macdonald, and R. K. Wayne. 2001. Carnivore conservation. Cambridge University Press, Cambridge, England, United Kingdom.

Griffin, A. S., M. Diquelou, and M. Perea. 2014. Innovative problem solving in birds: a key role of motor diversity. Animal Behaviour 92:221-227.

Griffin, A. S., and D. Guez. 2014. Innovation and problem solving: a review of common mechanisms. Behavioural Processes 109:121-134.

Knowlton, F. F., E. M. Gese, and M. M. Jaeger. 1999. Coyote depredation control: an interface between biology and management. Journal of Rangeland Management 52:398-412.

Laake, J., and E. Rexstad. 2008. RMark—an alternative approach to building linear models in MARK. Pages C1-C113 in E. G. Cooch, and G. C. White, editors. Program MARK: a gentle introduction. https://cran.r-project.org/ web/packages/RMark/index.html. Accessed 7 Sep 2018.

Lance, N. J., S. W. Breck, C. Sime, P. Callahan, and J. A. Shivik. 2011. Biological, technical, and social aspects of applying electrified fladry for livestock protection from wolves (Canis lupus). Wildlife Research 37:708-714.

McCullough, D. L. 1982. Behavior, bears, and humans. Wildlife Society Bulletin 10:27-33.

Mettler, A. E., and J. A. Shivik. 2007. Dominance and neophobia in coyote (Canis latrans) breeding pairs. Applied Animal Behaviour Science 102:85-94.

Miller, J. R., K. J. Stoner, M. R. Cejtin, T. K. Meyer, A. D. Middleton, and O. J. Schmitz. 2016. Effectiveness of contemporary techniques for reducing livestock depredations by large carnivores. Wildlife Society Bulletin 40:806-815.

Moreira-Arce, D., C. S. Ugarte, F. Zorondo-Rodríguez, and J. A. Simonetti. 2018. Management tools to reduce carnivore-livestock conflicts: current gap and future challenges. Rangeland Ecology \& Management 71:389-394.

Musiani, M., C. Mamo, L. Boitani, C. Callaghan, C. C. Gates, L. Mattei, E. Visalberghi, S. Breck, and G. Volpi. 2003. Wolf depredation trends and the use of fladry barriers to protect livestock in western North America. Conservation Biology 17:1538-1547.

Musiani, M., and E. Visalberghi. 2001. Effectiveness of fladry on wolves in captivity. Wildlife Society Bulletin 29:91-98.

R Core Team. 2018. R: a language and environment for statistical computing. Foundation for Statistical Computing, Vienna, Austria. http:// www.R-project.org/. Accessed 17 Oct 2017.

Rashford, B. S., T. Foulke, and D. T. Taylor. 2010. Ranch-level economic impacts of predation in a range livestock system. Rangelands 32:21-26.

Reader, S. M., and K. N. Laland. 2003. Animal innovation: an introduction. Pages 3-35 in S. M. Reader, and K. N. Laland, editors. Animal innovation. Oxford University Press, Oxford, England, United Kingdom.

Sacks, B. N., M. M. Jaeger, J. C. C. Neale, and D. R. McCoullough. 1999. Territoriality and breeding status of coyotes relative to sheep predation. Journal of Wildlife Management 63:593-605.

Šálek, M., L. Drahníková, and E. Tkadlec. 2015. Changes in home range sizes and population densities of carnivore species along the natural to urban habitat gradient. Mammal Review 45:1-14.

Scasta, J. D., B. Stam, and J. L. Windh. 2017. Rancher-reported efficacy of lethal and non-lethal livestock predation mitigation strategies for a suite of carnivores. Scientific Reports 7:14105.

Shivik, J. A. 2006. Tools for the edge: what's new for conserving carnivores. AIBS Bulletin 56:253-259.

Shivik, J. A., G. L. Palmer, E. M. Gese, and B. Osthaus. 2009. Captive coyotes compared to their counterparts in the wild: does environmental enrichment help? Journal of Applied Animal Welfare Science 12:223-235.

Tebbich, S., K. Sterelny, and I. Teschke. 2010. The tale of the finch: adaptive radiation and behavioural flexibility. Philosophical Transactions of the Royal Society London Series B Biological Sciences 365: 1099-1109.

Thornton, A., and J. Samson. 2012. Innovative problem solving in wild meerkats. Animal Behaviour 83:1459-1468.

United States Department of Agriculture - National Agricultural Statistics Service. 2011. Sheep and goats death loss and cattle death loss. USDA - NASS, Washington, D.C., USA. www.nass.usda.gov. Accessed 1 Jul 2018.

van Eeden, L. M., A. Eklund, J. R. Miller, J. V. López-Bao, G. Chapron, M. R. Cejtin, M. S. Crowther, C. R. Dickman, J. Frank, M. Krofel, and D. W. Macdonald. 2018. Carnivore conservation needs evidence-based livestock protection. PLoS Biology 16(9), e2005577.

Woodroffe, R., and J. R. Ginsberg. 1998. Edge effects and the extinction of populations inside protected areas. Science 280:2126-2128.

Woodroffe, R., S. Thirgood, and A. Rabinowitz. 2005. The impact of human-wildlife conflict on natural systems. Pages 1-12 in R. Woodroffe, S. Thirgood, and A. Rabinowitz, editors. People and wildlife, conflict or coexistence? Cambridge University Press, New York, New York, USA.

Young, J. K., E. Miller, and A. Essex. 2015. Evaluating fladry designs to improve utility as a nonlethal management tool to reduce livestock depredation. Wildlife Society Bulletin 39:429-433.

Young, J. K., J. Steuber, A. Few, A. Baca, and Z. Strong. 2018. When strange bedfellows go all in: a template for implementing non-lethal strategies aimed at reducing carnivore predation of livestock. Animal Conservation. https://doi.org/10.1111/acv.12453.

Associate Editor: Hinton. 